\title{
Logic Artificial Intelligence Application for the Students Individual Trajectories Introduction
}

\author{
Larisa E. Adamova ${ }^{1}$ and Oleg O. Varlamov ${ }^{2 *}$ \\ ${ }^{1}$ Russian New University, Radio str. 22, Moscow, 105005, Russia \\ ${ }^{2}$ Bauman Moscow State Technical University, 2nd Baumanskaya str., 5/1, 105005, Moscow, Russia
}

\begin{abstract}
The individual trajectories and other student learning individualization forms introduction in engineering education are becoming an important competitive university advantage. However, you should be mindful of the choices of learning paths within the framework of requirements of Federal State Educational Standards (FSES): to receive a diploma the student must fulfill all requirements of the FSES. Individualization cannot be arbitrary and must fit within the established framework of the curriculum. Students can study more than the established requirements of the FSES on an individual program. On the other hand, within the established restrictions of the FSES, there are enough alternatives for individualized training to choose the specialization of a certain professional area. For example, for students studying information technology, this specialization can be a choice between different economy sectors: banks, telecommunications, industrial production, logistics, aircraft and rocket engineering, car industry, Internet companies, social networks, etc. If we take developing computer technologies as a basis, then individualization can consist in a more detailed study of one area in IT: databases; expert systems; data security; distributed registries; artificial intelligence (AI); machine learning and image recognition; understanding of natural language; automated systems management and technological processes; robotics, etc. As we can see, opportunities for individualization of training for students exist even within the strict framework of training standards. The paper provides examples of such individualization of training with BMSTU students. Practical work has shown that individualization complicates the work and increases the time spent by university staff on managing trajectories in student learning. The achievements of mivar technologies of logical artificial intelligence allow automating routine operations for managing students' individual trajectories. In general, artificial intelligence can help in almost all tasks of engineering education in the transition to continuous people training "through life".
\end{abstract}

\footnotetext{
* Corresponding author: ovarlamov@gmail.com
} 


\section{Introduction}

The problem of implementing students' individual trajectories in engineering education is relevant. In general, education individualization is well studied in the pedagogical literature. For example, Shaposhnikova N. Yu. gives the analysis of various interpretations of these trajectories in the work [1]. Goncharova E. V. and Chumicheva R. M. [2] write that the student should be able to make an independent choice and implement their individual educational program, and teachers should provide pedagogical support for the student's self-realization. In his work [3] Bochkareva Sm. analyzes the individual trajectory of a student's development as a line of his movement in personality self-development and reveals the connection of the learning process with changes in the personality of such a student which will ultimately help him soberly correlate his strength and capabilities with various tasks and with the requirements of management and colleagues. Besides the concept of an individual route, Labunskaya N. A. introduces "a generalized educational route that includes a full set of stages and periods common to the array of students in the process of obtaining education and interacting with colleagues and the university" [4]. Grinko M. A. [5] suggests that besides the above concepts, consider the student's learning individual trajectory, which comprises a person-oriented organization of all the student's educational activities, taking into account the educational process. Note that new forms of student assessment are also being developed, such as portfolios [6]. The survey of Russian university students confirms that at least some students strive to build individual educational trajectories, but there are also various difficulties for universities that do not allow for the widespread individualization of training of Russian University students [7].

It is important to emphasize that such students' education individualization must meet educational standards, for example, self-establishing (SES) for BMSTU. It turns out that it is necessary to take into account the restrictions on the choice of learning paths within the requirements of FSES: to get a diploma, a student must meet all the requirements of the Federal State Educational system. Individualization cannot be arbitrary and must fit within the established framework of the curriculum. Students can study more than the established requirements of the FSES on an individual program. On the other hand, within the established restrictions of the FSES, there are still quite a lot of opportunities for individualization of training to choose the specialization of a certain professional area. For example, for students studying information technology, this specialization can be a choice between different economy sectors: banks, telecommunications, industrial production, logistics, aircraft and rocket engineering, car industry, Internet companies, social networks, etc. If we take developing computer technologies as a basis, then individualization can consist in an enhanced study of one area in IT: databases; expert systems; data security; distributed registries; artificial intelligence; machine learning and image recognition; natural language understanding; automated systems and technological processes management; robotics, etc. As we can see, opportunities for individualization of training for students exist even within the strict framework of training standards.

On the example of the IU-5 subdepartment, we can show how wide a range of opportunities for students' learning individualization. The subject of evolutionary databases and knowledge [8] is universal, but it is also supplemented by expert systems [9]; systems for understanding the natural Russian language [10]; decision-making systems for autonomous road vehicles [11]; systems for rapid summation of numbers [12]; automated control systems [13]. At the broader scientific level of modern technologies, research is being conducted in hybrid intelligent information systems [14], which study metagraphs [15]; cognitive architectures on them [16]; cognitive visualization [17]; neural networks [18]; news analysis systems architectures [19]; signal generation in computational 
intelligence [20]; semantic complex event processing [21]; disease prediction for medical institutions [22].

It is important to emphasize that at the IU-5 subdepartment, many students at the graduation time (2nd year of the master's degree) have scientific publications in RSCI, and the most successful ones in Scopus, for example, in the following areas: planning of actions of robotic complexes (RC) [23]; application of mivar technologies of logical artificial intelligence for autonomous cars [24]; road accidents modeling and mathematical reconstruction [25]; artificial intelligence ethical aspects development [26]; compliance with traffic rules monitoring [27].

Thus, if the graduate university department conducts active scientific work in the most modern research areas, then students have additional opportunities to individualize their training and achieve success in subsequent employment.

\section{Individualization in IT and Al Education}

In information technology teaching, the learning material changes dynamically, following the emergence of new information processing technologies, programming languages, and hardware. All this fully applies to the study of artificial intelligence modern methods and models. Besides, at present, senior students must be able to work in a team, make presentations, write scientific reports and even articles. This imposes additional requirements on teachers but has a positive effect on the subsequent successful employment of graduates.

Everyone understands that in modern conditions in Russia, and many other countries, IT specialists are very popular, and they have almost no problems finding a good job after graduation. But this applies only to those graduates who studied well and received the required knowledge, skills, and abilities. In fairness, we must agree that the competition for admission to good universities in IT is almost maximum. And if we take the popularity of the IT specialist profession over the past 20 years, it has never left the "top three" in terms of salaries and demand from employers. Although many other specialties changed, became popular, then became saturated and replaced with other specialties. With the IT development, the required specialists number is constantly increasing, as is the number of "specializations" within this IT industry.

There is an aim regularity in the expansion of demand for IT specialists, because of the almost total automation of the entire industry, the transition to industry 4.0, which recently started in our country with the digitalization and "digital transformation" of the entire Russian economy, and the huge demand for the development of artificial intelligence in all its varieties: from neural network machine learning through logical decision support systems to social problems and robot ethics. Currently, all experts in economic forecasting recognize that the demand for IT specialists will only expand, new professions and various narrow specialties will arise. However, the AI development allows you to gradually simplify many tasks and functions in the IT industry, which reduces the qualification requirements for some of the most common "narrow specialties" and allows more people to work in this industry.

One example of expanding specialties by reducing requirements or significantly changing them is a "specialist" in neural network training, whose task is to view images and put text labels under these images. This way huge "data sets" are created for various neural networks subsequent training. And tasks in this area can be simple, for example, a wellknown example of creating sets of images of cats and dogs. In many ways, this reduction in requirements is for the complexity of the artificial intelligence methods themselves, the creation of new AI systems, which then need to be trained on fairly simple examples for ordinary people. Adults raise and train their children, and many AI systems can now be 
trained on the same principle. Another example of expanding IT specialties is creating three-dimensional virtual figures of various characters or environments for the gaming industry or movie production. This requires different skills and competencies than writing code for various programs. Interface designers also belong to the same class of "artistic" IT professionals.

The example of the IU-5 subdepartment shows that an important role for the employment of graduates is also played by the possibility of passing practical training in their potential work, after which the student gets the opportunity to purposefully prepare a final qualifying work in the subject area of a potential employer. And here the individualization of training is maximum, but it is necessary to meet all the qualification requirements of the FSES.

If we talk about the development of the most modern professions in IT, almost all of them are related to scientific research and working in different teams. Today's young people in Russia do not want to do science, but the requirements of employers are getting tougher and tougher: everyone needs active knowledgeable specialists with critical analytical thinking, capable of independent work in various teams, who can make presentations and defend their developments, and also constantly self-learning. Employers do not talk about scientific publications, but the entire set of requirements corresponds to the requirements for scientists who are able not only to solve theoretical problems but also to bring them to practical engineering implementations. And the requirement for self-study corresponds to the scientific skill for continuous study of new products, their critical awareness, and practical development.

Moreover, modern education technologies allow almost anywhere in the world to get access to the most up-to-date scientific information via the Internet and make it possible to discuss it with any colleagues. The number of different training courses is growing in an avalanche and modern specialists must be able to choose the main thing and quickly learn new skills. We would like to emphasize that in such a rapidly changing IT world, only fundamental mathematical education can enable students to understand all the basic laws of the scientific development of the world and lay the right foundation for further continuous self-learning through "all life". Thus, it is a serious theoretical mathematical education that is currently the most practical for employment in a good job and continuous growth in professional terms.

Note that when some students in the study group begin to perform scientific work and make scientific reports and reports, then gradually most students join them. Thus, students are convinced in practice that scientific work is interesting, useful and capable of all students. Of course, not all students have time to prepare serious scientific publications for RSCI and even "VAK" journals, but most of them have time to take part in scientific conferences. We believe that preparing scientific publications is one of the successful students' educational trajectory individualization forms because our students (under the teacher's guidance) themselves create new scientific knowledge and their practical implementation in the software packages form.

We want to note that the automation and artificial intelligence technologies rapid development leads to a new stratification in the level of mastering the profession: first, AI replaces fairly expensive middle-level specialists, while the best AI experts cannot yet be replaced, and the most simple functions for economic reasons remain for poorly trained workers with low incomes. This stratification is still being formed, and it is not too late to take measures to urgently train "middle-class" people and raise them to the highest level of expert knowledge. This also requires a serious (mathematical) education, huge labor costs for self-learning and "iron will" to overcome all obstacles and get relevant skills and abilities. By the way, this method of self-development is also a scientific activity example. Therefore, independent scientific work skills are becoming mandatory for a very wide 
range of specialists and are an important factor in improving their competitiveness for our current and future students. Thus, on the one hand, AI makes life more difficult for many people, and it provides new opportunities and facilitates self-development and training for everyone who wants to improve their knowledge, skills, and abilities.

\section{Student Education Individualization Features}

To analyze the possibilities of using artificial intelligence systems in education [1-7], it is important to fix the following statements:

- the student makes a plan for himself, which should comprise carefully written elements, including possible obstacles and hindrances;

- $\quad$ the student should receive support from teachers, and not just in the form of a negative or positive assessment of the actions performed, but also a detailed analysis of possible alternatives;

- $\quad$ it should aim this plan at this plan should be aimed at both the professional and personal development of the student. It is impossible to reflect professional perspectives and competencies without taking into account the individual psychological properties of the individual which determine the mental activity of the individual;

- $\quad$ the individual plan should take into account the student's personal, educational, and professional interests, and their needs and requests. Special attention should be paid to the development and maintenance of internal motivation, in which the motivating force becomes a cognitive interest that allows you to shift the original external motive to the goal of learning;

- a student's individual educational route is a path based on an individual educational program that defines stages, and time and educational criteria. The quality of using these criteria directly depends on the feedback received from the student, both when building the initial educational route and when studying interval results;

- the student' individual educational trajectory is an individual path in education, implemented by the subject (student) independently, but with constant pedagogical support for his self-determination and self-realization. When we talk about independence, it is necessary to note that we need not just support from mentors, but also intermediate control: pre-planned milestones, where the report on the route passed takes place. Note that intermediate control can be implemented using AI systems. Besides, the most objective assessment of their successes and failures at various stages of the movement to the goal will make it possible to adjust the educational trajectory with minimal losses;

- the trajectory is aimed at implementing individual aspirations, developing life strategies, and forming the foundations for the individual creative and professional development of the student's personality. Speaking about life strategy, it is necessary to take into account that the so-called ideal image of the future and optimal prospects may differ even among representatives of the same generation, and among representatives of the same age and gender group.

Consequently, from the AI point of view, we can distinguish three levels of design education for every student:

1) individual educational program of the student;

2) program specification is performed in the route;

3 ) the educational program in the course of training is implemented in the form of a student's trajectory when the selected route can be adjusted.

It should be recalled that to get a diploma, each student must meet all the FSES requirements, so any student educational trajectory must meet the FSES requirements. As you can see, individualization of education generates a huge number of routine operations 
for dispatching and managing student trajectories, including monitoring students' knowledge and compliance with all the FSES requirements.

\section{Logical Al for Individualizing Student Learning Possibilities Analysis}

Let's move on to the logical artificial intelligence possibilities analysis, the most powerful embodiment of which is currently mivar technologies [8], combining "gnoseological evolutionary databases "Thing-Property-Relation" and mivar knowledge bases with linear computational complexity of logical inference" [9], designed for the accumulation and processing of knowledge in a single formalism at a speed of more than a million products per second on conventional computers. For individualization of students' education, the mivar technologies possibilities implemented in practice for understanding and processing Russian-language texts [10], autonomous road vehicles [11] and decision-making systems for planning robot actions [23] are of interest.

The individualization peculiarities analysis of students' education revealed a contradiction between the students' desires to study certain disciplines and the requirements of the FSES for a mandatory set of academic disciplines. This contradiction can be represented in the formalism of metagraphs in the following form: all the academic disciplines required by the FSES are represented as metavertexes, which may include several graph vertices. The simple graph vertices will represent different variants of the same academic discipline, which is allowed by the FSES, which forms the graph metavertex. In the simplest case, a metavertex can contain only one "elementary" vertex.

For each educational discipline, a working program of the discipline (WPD) is compiled, which specifies all the academic disciplines that the student must study before starting a new academic discipline. We get a directed graph in which all academic disciplines are connected by edges (arcs) that reflect the sequence of studying these disciplines. In addition to mandatory academic disciplines in the FSES, universities may offer students elective courses, which can also be combined based on "academic proximity " in metavertexes. Then in the General metagraph of academic disciplines of the university, you can distinguish two types of metavertexes:

1) "FSES metavertexes"

2) "additional metavertexes".

For additional metavertexes, there are also requirements for the development of the WPD and specifying in them those academic disciplines that students must to study before the beginning of the development of this discipline.

In our metagraph appear metaedges, which include edges between vertices of the same metavertexes; edges that connect vertices in different metavertexes. We get a fairly complex " WPD metagraph" for the university, especially if we take into account large universities that teach hundreds of training programs. Additional complexity will be created because students may want to study subjects that are, relatively speaking, included in other educational programs. For example, an IT student might want to study some courses in psychology or economics. The difficulty is that these disciplines are not in his educational program. There may also be a situation when a student has studied a "short version" of discipline in their educational program, they are interested in IT and decided to learn more detailed material in this discipline, but in a different educational program. For example, a student studied the basics of accounting and then wanted to learn more about the study material on economics. There can be many such options for individualized training.

Additional restrictions will be the academic discipline teaching schedule; the need to master the "previous WPD" disciplines; and the need to pass an exam or get a test for this discipline. Distance learning via the Internet can help here. But any possibility of a student 
creates additional difficulties for the academic part, the department and the dean's office. Now we are considering the possibility of a student studying a discipline through online courses of other universities with the possibility of transferring such a discipline in their university. Accordingly, the department methodologists should study another university WPD and compare it with their own, and then make a decision about the transfer for this student. There may be situations when a student has studied and passed an exam in a subject that is not in their educational program, and then the question arises on how to make this assessment in the student's diploma. It is possible to use the new student portfolio tool for this purpose. In this portfolio, the student will download all the received testimony of studied subjects and received marks, and the main place of education in the diploma will bear only the marks got by the student they mastered the educational program by the FSES requirements.

Thus, a student's educational metagraph can even combine academic disciplines from different universities. After receiving a diploma, such a student, becoming a specialist, can continue to "build up" their educational metagraph, adding additional training courses and other development results. Then the student's portfolio moves to the specialist's portfolio and continues its development. This fully meets the modern requirements of lifelong education for adults "through life".

So, each university based on its educational programs will have a metagraph of possible routes of education for its students. Students will plan individual routes taking into account all the possibilities and limitations. If all metagraphs are represented in the view of mivar networks, then the mivar expert system of KESMI Wi!Mi! [9] will be able to automatically build individual routes for students, and then track their performance in the students' educational trajectories form.

Also, mivar logical AI technologies will automatically implement almost all routine operations for the compilation and automated management of students' individual routes and trajectories. Besides, AI will allow you to solve a variety of routine tasks for the transition to a continuous "life-long" people education.

For AI to help universities ensure the individualization of student learning, research will continue in the following areas.

First, at the beginning of training, the student can take with an AI test for the formation of their training route.

Second, during the training process, AI can help university staff and students manage all students' trajectories and track the implementation of the curriculum, taking into account the FSES requirements.

Third, AI can help teachers (or independently) evaluate students' knowledge and take tests, boundary control tasks, and exams.

As already noted, the AI development field is rapidly developing and creating new opportunities for individualized student learning. At the same time, AI sets new strict requirements for employees, constantly raising the requirements for knowledge, skills, and abilities of modern specialists. Thus, everything again depends on the person who needs to constantly learn and improve their skills.

\section{Conclusion}

The students' individual trajectories introduction in engineering education improves the education quality and creates additional opportunities for students to take into account in the portfolio to improve their competitiveness and job search.

However, education individualization generates a huge number of routine operations and options for creating educational routes and trajectories that can be formalized in the form of mivar networks. 
Mivar technologies of logical artificial intelligence will allow, in full compliance with the FSES requirements, and automate routine management of the students' individual trajectories, and will also be able to help with other tasks to enable continuous, "lifelong" training.

\section{References}

1. N.Yu. Shaposhnikova, Individual'naya obrazovatel'naya traektoriya studenta: analiz traktovok ponyatiya [Student's Individual], Pedagogicheskoe obrazovanie v Rossii [Pedagogical education in Russia], № 5, pp. 39-44 (2015).

2. E.V. Goncharova, R.M. Chumicheva, Organizaciya individual'noj obrazovatel'noj traektorii obucheniya bakalavrov [Development of individual Learning Trajectories for Bachelor Students], Vestnik NGGU, № 2, pp. 3-11 (2012).

3. S.M. Bochkareva, Metody, sredstva $i$ tekhnologii $v$ t'yutorskom soprovozhdenii individual'noi traektorii razvitiya studenta [Methods, tools and technologies in tutoring accompanied by individual trajectory of student development], Pedagogika i psihologiya kak resurs razvitiya sovremennogo obshchestva : sb. st. 2-i Mezhdun. nauch.-prakt. kon. (Ryazan', 7-9 okt. 2010 g.) [Pedagogics and psychology as a resource for the development of modern society: collection of papers of the 2nd International. science.- prakt. Cohn. (Ryazan, 7-9 Oct. 2010)], Ryazan, pp. 320-325 (2010).

4. N.A. Labunskaya, Individual'nyj obrazovatel'nyj marshrut studenta: podhody $k$ raskrytiyu ponyatiya [The Student's Individual Route: Approaches to the Concept], Izvestiya RGPU im. A. I. Gercena, № 3, pp. 79-90 (2002).

5. M.A. Grin'ko, Proektirovanie individual'nyh traektorǐ obucheniya inostrannomu yazyku studentov pedagogicheskih vuzov [Design Individual Trajectories of Teaching a Foreign Language to Students of Pedagogical Higher Schools], Vestnik Adygeĭsk. gos. un-ta. Ser. 3: Pedagogika i psihologiya, № 3, pp. 18-22 (2011).

6. N.Yu. Shaposhnikova, Opyt vvedeniya portfolio dlya ocenki dostizhenij i razvitiya studentov $v$ universitetah Velikobritanii [Experience of Portfolio Introduction for Estimations of Achievements and Development of Students of UK universities], Otechestvennaya i zarubezhnaya pedagogika [Domestic and Foreign Pedagogy], vol. 1, №1(46), pp. 94-107 (2018).

7. N.Yu.Shaposhnikova, Sostoyanie problemy realizacii individual'nyh obrazovatel'nyh traektorij studentov $v$ vysshej shkole [The State of the Problem of Student's Individual Educational Paths Realization in Russian Universities], Nauka o cheloveke: gumanitarnye issledovaniya [The Man Science: Humanitarian Research], №2(24), pp. 105-111 (2016).

8. O.O. Varlamov, Evolyucionnye bazy dannyh $i$ znanij dlya adaptivnogo sinteza intellektual'nyh sistem. Mivarnoe informacionnoe prostranstvo [Evolutionary databases and knowledge for adaptive synthesis of intelligent systems. Mivar information space]. Radio i svyaz' [Radio and communications], 288 pp., ISBN 5-25601650-4 (2002).

9. O.O. Varlamov, Wi!Mi Expert System Shell as the Novel Tool for Building KnowledgeBased Systems with Linear Computational Complexity, International Review of Automatic Control, 11(6), 314-325 (2018). DOI: https://doi.org/10.15866/ireaco.v11i6.15855. 
10. L.E. Adamova, O.O. Varlamov, V.G. Osipov, D.A. Chuvikov, O prakticheskoj realizacii mivarnogo virtual'nogo russkoyazychnogo tekstovogo konsul'tanta $v$ bankovskoj sfere [On the practical implementation of the mivar virtual Russianlanguage text consultant in the banking sector], Izvestiya Kabardino-Balkarskogo nauchnogo centra RAN [News of Kabardino-Balkar scientific center of the Russian Academy of Sciences], № 6-2 (86), pp. 10-17 (2018).

11. S.S. Shadrin, O.O. Varlamov, A.M. Ivanov, Experimental autonomous road vehicle with logical artificial intelligence, Journal of Advanced Transportation, vol. 2017, 10 p. (2017). DOI: https://doi.org/10.1155/2017/2492765.

12. O.O. Varlamov, Exhaustive elementary-incremental summing up of numbers with linear computational complexity Avtomatizatsiya i Sovremennye Tekhnologii, 1, pp. 34-41 (2003).

13. A. Ostroukh, N. Surkova, O. Varlamov, V. Chernenky, A. Baldin Automated process control system of mobile crushing and screening plant Journal of Applied Engineering Science, 16(3), pp. 343-348 (2018).

14. V. Chernenkiy, Y. Gapanyuk, V. Terekhov, G. Revunkov, Y. Kaganov, The hybrid intelligent information system approach as the basis for cognitive architecture Procedia Computer Science, 145, pp. 143-152 (2018).

15. V.M. Chernenkiy, Y.E. Gapanyuk, G.I. Revunkov, Y.T. Kaganov, Y.S. Fedorenko, S.V. Minakova, Using metagraph approach for complex domains description, CEUR Workshop Proceedings 2022, pp. 342-349, (2017).

16. V. Chernenkiy, Y. Gapanyuk, G. Revunkov, Y. Kaganov, Y. Fedorenko, Metagraph Approach as a Data Model for Cognitive Architecture Advances in Intelligent Systems and Computing, 848, pp. 50-55, (2019).

17. V.I. Terekhov, I.M. Chernenky, S.V. Buklin, A.R. Yakubov, Cognitive Visualization in Management Decision Support Problems Optical Memory and Neural Networks (Information Optics), 28(1), pp. 27-35 (2019).

18. A.V. Burdakov, A.O. Ukharov, M.P. Myalkin, V.I. Terekhov, Forecasting of influenza-like illness incidence in amur region with neural networks Studies in Computational Intelligence, 799, pp. 307-314 (2019).

19. Y. Gapanyuk, I. Latkin, S. Chernobrovkin, A. Leontiev, G. Ozhegov, A. Opryshko, M. Myalkin, Architecture and implementation of an intelligent news analysis system, CEUR Workshop Proceedings 1975, pp. $41-55$ (2017).

20. M. Taran, G. Revunkov, Y. Gapanyuk, The hybrid intelligent information system for poems generation, Studies in Computational Intelligence, 856, pp. 78-86 (2020).

21. Y.E. Gapanyuk, The Semantic Complex Event Processing Based on Metagraph Approach Advances in Intelligent Systems and Computing, 948 pp. 99-104 (2020).

22. A.V. Burdakov, A.O. Ukharov, M.P. Myalkin, V.I. Terekhov, Forecasting of influenza-like illness incidence in amur region with neural networks, Studies in Computational Intelligence, 799, pp. 307-314 (2019).

23. O.O. Varlamov, D.V. Aladin, Successful application of mivar expert systems for MIPRA - solving action planning problems for robotic systems in real time, Radio industry (Russia), 29(3), pp. 15-25 (2019). DOI: https://doi.org/10.21778/2413-95992019-29-3-15-25.

24. O.O. Varlamov, D.A. Chuvikov, D.V. Aladin, L.E. Adamova, V.G. Osipov, Logical artificial intelligence Mivar technologies for autonomous road vehicles, IOP Conference Series: Materials Science and Engineering, 534(1), 012015 (2019). 
25. D.A. Chuvikov, O.O. Varlamov, D.V. Aladin, V.M. Chernenkiy, A.V. Baldin, Mivar models of reconstruction and expertise of emergency events of road accidents, IOP Conference Series: Materials Science and Engineering, 534(1), 012007 (2019).

26. O.O. Varlamov, D.A. Chuvikov, L.E. Adamova, M.A. Petrov, I.K. Zabolotskaya, T.N. Zhilina, Logical, Philosophical and Ethical Aspects of AI, Medicine International Journal of Machine Learning and Computing (IJMLC), 9(6), pp. 868-873 (2019).

27. D.V. Aladin, O.O. Varlamov, D.A. Chuvikov, V.M. Chernenkiy, E.A. Smelkova, A.V. Baldin, Logic-based artificial intelligence in systems for monitoring the enforcing traffic regulations, IOP Conference Series: Materials Science and Engineering, 534(1), 012025 (2019). 